\title{
Household chemicals, persistent wheezing and lung function: effect modification by
} atopy?

\author{
J. Henderson*, A. Sherriff*, A. Farrow" ${ }^{\#}$ and J.G. Ayres
}

ABSTRACT: The aims of the present study were to assess the effects of maternal use of domestic chemicals during pregnancy on wheezing and lung function in children aged $\leqslant 8.5$ yrs and to explore the potential modifying effect of atopy.

In the Avon Longitudinal Study of Parents and Children, a cohort study, a maternal composite household chemical exposure (CHCE) score was derived. Wheezing phenotypes from birth to age 7 yrs were assigned on the basis of reported wheeze. Lung function (forced expiratory volume in one second (FEV1), forced vital capacity (FVC), forced midexpiratory flow between 25 and $75 \%$ of FVC (FEF25-75\%)) was measured at age 8.5 yrs; and atopy by skin-prick tests at age 7.5 yrs. Multinomial logistic and linear regression models assessed the relationship between wheezing outcomes, lung function and CHCE score, and interactions with atopy.

Increased CHCE score was associated with early- ( $<18$ months) and intermediate- (1830 months) persistent and late-onset (>30 months) wheezing in nonatopic children (adjusted odds ratio per z-score of CHCE (95\% confidence interval) 1.41 (1.13-1.76), 1.43 (1.02-2.13) and 1.69 (1.19-2.41), respectively). Increasing CHCE score was associated with decrements in FEV 1 and FEF $25-75 \%$.

Higher domestic chemical exposure during pregnancy was associated with persistent wheeze and lung function abnormalities in nonatopic children. This may result from pre-natal developmental effects or post-natal irritant effects on the developing airway, but is unlikely to be mediated through increased hygiene in the home.

KEYWORDS: Atopy, Avon Longitudinal Study of Parents and Children, chemicals, children, wheezing

I $\mathrm{n}$ a previous study SHERRIFF et al. [1] reported that frequent use of household chemicals by pregnant females was associated with persistent wheezing in their offspring in early childhood. There is a paucity of research into the possible effects of domestic chemical exposure in young children who spend a large proportion of their time indoors and who may be subject to a range of co-exposures in the home. However, despite several methodological differences, evidence from occupational studies can guide research into community and domestic exposures to indoor pollutants [2]. There is now substantial evidence of an increased risk of asthma in domestic and office cleaning workers that is likely to represent a direct causal effect of chemical exposure associated with these occupations [3]. Additionally, other observational and case-control studies have reported positive associations

For editorial comments see page 489 . between workplace exposure and a range of outcomes including asthma [4,5], occupational asthma [6-8], airway inflammation [9] and chronic obstructive pulmonary disease (COPD) [10]. A population-based case-control study in Australia [11] has recently reported higher levels of domestic exposure to volatile organic chemicals (VOCs) in children with asthma compared with controls.

One possible mechanism for this finding is that homes with more chemical exposure were cleaner and the risk of developing T-helper cell type 2-based diseases, such as asthma, was increased in association with reduced exposure to environmental antigens in early childhood.

The aims of the present study were to investigate: 1) the effects of maternal chemical use during pregnancy on wheezing patterns in children aged $\leqslant 7$ yrs; 2) whether increasing use is associated with decrements in lung function at age $8.5 \mathrm{yrs}$; and 3) whether atopy modifies these associations.

\section{AFFILIATIONS}

*Avon Longitudinal Study of Parents and Children, University of Bristol, Bristol,

\#School of Health Sciences and Social Care, Brunel University, Uxbridge, and

"Dept of Environmental and Occupational Medicine, Liberty Safe Work Research Centre, University of Aberdeen, Aberdeen, UK.

CORRESPONDENCE

J. Henderson

Avon Longitudinal Study of Parents and Children

Dept of Community-based Medicine 24 Tyndall Ave

University of Bristol Bristol BS8 1BR UK

Fax: 441173311704

E-mail: A.J.Henderson@bris.ac.uk

Received:

July 112007

Accepted after revision:

October 162007

\section{SUPPORT STATEMENT}

The UK Medical Research Council, the Wellcome Trust UK and the University of Bristol provide core support for ALSPAC. This article is the work of the authors and A. Sharriff and J. Henderson will serve as guarantors for contents.

STATEMENT OF INTEREST

None declared.

European Respiratory Journal Print ISSN 0903-1936 Online ISSN 1399-3003 


\section{METHODS}

\section{Study sample}

The Avon Longitudinal Study of Parents and Children (ALSPAC) [12] is a prospective study of 14,541 pregnancies. Females were enrolled as early in pregnancy as possible, on the basis of an expected date of delivery between April 1, 1991 and December 31, 1992, and place of residence within the three Bristol-based health districts of the former county of Avon, UK. There were 14,062 live births and 13,988 infants survived to $1 \mathrm{yr}$ of age. Ethical approval for the study was obtained from the ALSPAC Law and Ethics Committee and local research ethics committees.

\section{Data collection}

Wheezing

Questionnaires on wheezing patterns of the study child were completed by a parent or primary carer (usually the mother) at 6 months, 18 months, 30 months, 42 months and 81 months after birth. Each mother was asked whether the child had experienced wheezing with whistling on his/her chest during each of the study periods: 0-6 months; 6-18 months; 1830 months; 30-42 months; and 69-81 months. This information was used to identify six mutually exclusive patterns of wheeze between birth and age 7 yrs: 1) never wheezed, i.e. no wheezing at any of the five time-points; 2) early-onset transient wheeze, i.e. wheezed at 0-18 months but not at 69-81 months; 3) intermediate-onset transient wheeze, i.e. no wheeze at 0 18 months and wheeze at 18-42 months and no wheeze at 6981 months; 4) early-onset persistent wheeze, i.e. wheeze at 0-18 and 69-81 months; 5) intermediate onset persistent wheeze, i.e. no wheeze at 0-18 months and wheeze at 18-42 and 6981 months; and 6) late onset wheeze, i.e. onset of wheeze after 42 months and before 81 months.

\section{Atopy}

Skin-prick tests were performed at age 7.5 yrs to a panel of six allergens (house dust mite (Dermatophagoides pteronyssinus), cat, mixed grass, mixed nuts, peanut and milk) and to positive (1\% histamine solution) and negative (diluent) controls. Skin tests were carried out on the anterior surface of the left arm using new disposable sterile lancets for each allergen tested. The skin was pricked through a drop of allergen solution (ALK-Abelló, Hørsholm, Denmark), the allergen solutions were blotted off after 5 mins and the tests were read after a further 10 mins. The maximum weal diameter was measured and a second measurement performed at $90^{\circ}$ to the first. From these, the mean weal diameter was calculated. For the purpose of the present study, atopy was defined as any positive skinprick test to cat, mixed grass or house dust mite (weal diameter $\geqslant 1 \mathrm{~mm}$ with a negative diluent response).

\section{Lung function}

Lung function was measured by spirometry at age $8.5 \mathrm{yrs}$ using a Vitalograph ${ }_{\circledast} 2120$ hand-held pneumotachograph and computer-based analysis software (Spirotrac ${ }^{\circledR}$ IV; both from Vitalograph $_{\circledast}$, Maids Moreton, UK). Subjects were asked to postpone short-acting bronchodilators for $6 \mathrm{~h}$, long-acting bronchodilators, including oral bronchodilators and theophyilline, for $24 \mathrm{~h}$ and to avoid xanthine-containing beverages for $24 \mathrm{~h}$ prior to testing. Testing was carried out in a dedicated research clinic by a team of six research physiologists. An on-screen incentive was used and the interpretation of results was based on the American Thoracic Society [13]/European Respiratory Society [14] criteria for acceptability and reproducibility of maximal expiratory flow-volume curves. All flowvolume curves were inspected post hoc to ensure that adequate criteria were met. Results were obtained from the best of three technically acceptable flow-volume curves repeatable within $200 \mathrm{~mL}$ of forced vital capacity (FVC). The variables forced expiratory volume in one second (FEV1), FVC, forced midexpiratory flow between 25 and 75\% of FVC (FEF25-75\%) and forced expiratory flow at $75 \%$ of FVC were recorded and transformed to SD scores adjusted for age, sex and height.

\section{Household chemical exposure}

During pregnancy, females were asked to complete questionnaires on aspects of their health, environment and lifestyle. In particular, they were asked "During this pregnancy how often have you used the following (a list of 15 chemical-based products)?". Available responses were: not at all; less than once a week; about once a week; most days; and every day. From the initial list of 15 products included in the questionnaire, the 11 most frequently used ( $\geqslant 5 \%$ of study sample reported using the specific product) were selected. The products chosen (and the percentages of females using them) were: disinfectant $(87.4 \%)$; bleach $(84.8 \%)$; carpet cleaner $(35.8 \%)$; window cleaner $(60.5 \%)$; dry cleaning fluid $(5.4 \%)$; aerosols $(71.7 \%)$, turpentine/white spirit $(22.6 \%)$, air fresheners (spray, stick or aerosol; $68 \%$ ); paint stripper (5.5\%); paint or varnish $(32.9 \%)$; and pesticides/insect killers $(21.2 \%)$. A simple score for frequency of use of each product was derived: 0 for not at all; 1 for less than once a week; 2 for about once a week; 3 for most days; and 4 for every day. The scores for each product were summed to produce a composite household chemical exposure (CHCE) score for each respondent, which could range 0-44 (from no exposure to exposed to all 11 products daily). These scores were then standardised (subtract mean and divide by SD z-scores) in order to make comparisons of effect sizes between analyses.

In order to investigate whether VOC-containing chemicals were more likely to be associated with the various outcomes, the scores derived for VOC- and nonVOC-containing chemicals were analysed independently.

\section{Potential confounding variables and effect modifiers}

A number of variables were considered as potential confounders of the association between wheezing, lung function and CHCE score, and are presented in table 1 along with their associations with CHCE. Atopy, as defined previously, was considered a possible effect modifier of the association between $\mathrm{CHCE}$ score and wheezing and lung function.

\section{Statistical methods}

Multinomial logistic regression models were used to analyse associations between CHCE z-score and patterns of wheeze using the never-wheezed group as the reference category. All models were adjusted for the aforementioned list of potential confounders that were associated with both outcome and exposure variables, but were not considered to be on the causal pathway. General linear models were used to analyse the effect of CHCE z-score on lung function SD scores (FVC, FEV1, 
TABLE 1 Characteristics of the study sample according to confounding variables and their association with Composite Household Chemical Exposure (CHCE) score

\begin{tabular}{|c|c|c|c|}
\hline & Young males & Young females & CHCE \\
\hline \multicolumn{4}{|c|}{ Maternal smoking during pregnancy cigarettes $\cdot$ day $^{-1}$} \\
\hline None & 3057 (85.2) & $2858(85.4)$ & $9.1 \pm 4$ \\
\hline $1-9$ & $234(6.5)$ & $202(6.0)$ & $10.3 \pm 4$ \\
\hline$\geqslant 10$ & $296(8.3)$ & $286(8.5)$ & $11.1 \pm 4$ \\
\hline \multicolumn{4}{|c|}{ Exposure to environmental tobacco smoke } \\
\hline \multicolumn{4}{|l|}{ Damp housing } \\
\hline No & $1782(49.9)$ & $1752(52.2)$ & $9.6 \pm 4$ \\
\hline Yes & $1787(50.1)$ & $1607(47.8)$ & $9.1 \pm 4$ \\
\hline \multicolumn{4}{|l|}{ Pets in home } \\
\hline No & $1670(46.7)$ & $1555(46.2)$ & $9.1 \pm 4$ \\
\hline Yes & $1907(53.3)$ & $1810(53.8)$ & $9.8 \pm 4$ \\
\hline \multicolumn{4}{|c|}{ Maternal age at delivery yrs } \\
\hline$<25$ & $521(14.0)$ & $539(15.6)$ & $10.4 \pm 4$ \\
\hline$\geqslant 25$ & $3190(86.0)$ & $2912(84.4)$ & $9.2 \pm 4$ \\
\hline \multicolumn{4}{|c|}{ Maternal highest education } \\
\hline None/CSE & $487(13.3)$ & $464(13.6)$ & $10.7 \pm 4$ \\
\hline Vocational & $315(8.6)$ & $281(8.3)$ & $10.6 \pm 4$ \\
\hline O-level & 1325 (36.3) & $1194(35.1)$ & $9.9 \pm 4$ \\
\hline A-level & $938(25.7)$ & $902(26.5)$ & $8.9 \pm 4$ \\
\hline Degree & $590(16.1)$ & $563(16.45)$ & $7.1 \pm 4$ \\
\hline \multicolumn{4}{|l|}{ Housing tenure } \\
\hline Mortgage owned & 3025 (84.6) & $2788(82.8)$ & $9.2 \pm 4$ \\
\hline Council rented & $306(8.6)$ & $303(9.0)$ & $11.3 \pm 5$ \\
\hline 0 & $1651(45.3)$ & $1569(46.4)$ & $9.1 \pm 4$ \\
\hline 1 & $1290(35.4)$ & $1227(36.3)$ & $9.6 \pm 4$ \\
\hline$\geqslant 2$ & $707(19.4)$ & $585(17.3)$ & $9.8 \pm 4$ \\
\hline \multicolumn{4}{|c|}{ Maternal hours worked outside home } \\
\hline Doesn't work & $1780(51.2)$ & $1657(51.1)$ & $9.5 \pm 4$ \\
\hline$<10$ & $276(7.9)$ & $278(8.6)$ & $9.3 \pm 4$ \\
\hline $10-20$ & $748(21.5)$ & 732 (22.6) & $9.5 \pm 4$ \\
\hline $20-30$ & $329(9.5)$ & $266(8.2)$ & $9.1 \pm 4$ \\
\hline$\geqslant 30$ & $345(9.9)$ & 309 (9.5) & $8.7 \pm 4$ \\
\hline \multicolumn{4}{|l|}{ Season of questionnaire } \\
\hline January-April & $1461(39.7)$ & $1377(40.3)$ & $9.2 \pm 4$ \\
\hline May-August & 1226 (33.3) & 1137 (33.3) & $9.8 \pm 4$ \\
\hline September-December & $991(26.9)$ & $902(26.4)$ & $9.3 \pm 4$ \\
\hline
\end{tabular}

Data are presented as $n(\%)$ or mean \pm SD.

FEF25-75\%) while controlling for confounders. CHCE z-score was considered as a continuous exposure variable in the first instance. However, wheezing patterns and lung function of children whose mothers scored lowest in the CHCE score $(<10$ th centile) were also compared with children whose mothers scored highest ( $>90$ th centile). In order to determine 
whether atopy modified the observed associations with $\mathrm{CHCE}$ score, all outcome variables were tested using standard interaction tests within each of the models.

In order to assess whether a linear relationship with each wheezing pattern was appropriate, the CHCE score was first fitted as a continuous factor in a model and then as a categorical factor. For the categorical factor, the CHCE score was split into deciles as there were only 28 discrete $\mathrm{CHCE}$ scores reported, 10 groups providing adequate numbers per group. A likelihood ratio test statistic was used to determine whether there was significant departure from linearity in the relationship between $\mathrm{CHCE}$ score and wheezing patterns.

\section{RESULTS}

Of the 13,988 ALSPAC children alive at $1 \mathrm{yr}, 7,162$ (51\%) could be categorised into one of the six wheezing groups and had information available on chemical exposure in the home during pregnancy. Between birth and age 7 yrs, 4,072 (56.9\%) children never wheezed, 1,909 $(26.7 \%)$ had early-onset transient wheeze, $452(6.3 \%)$ had intermediate-onset transient wheeze, $413(5.8 \%)$ had early-onset persistent wheeze, 149 $(2.1 \%)$ had intermediate-onset persistent wheeze and 167 $(2.3 \%)$ had late-onset wheeze.

In this sample, the CHCE score ranged 0-30 with a mean \pm SD of $9.4 \pm 4.1$ and was approximately normally distributed.

Lung function measurements (with associated CHCE scores) were available for 6,359 children, of whom 100 reached FVC within $1 \mathrm{~s}$ and had no FEV1 measurement calculated. All measurements are presented as SD units.

In total, 6,277 children underwent skin-prick testing at age $7.5 \mathrm{yrs}$ and had an associated CHCE score (21.6\% atopic); the mean CHCE score in atopic subjects $(9.4 \pm 4.0)$ was similar to that in nonatopic subjects $(9.5 \pm 4.1 ; \mathrm{p}=0.8)$.

Table 1 presents characteristics of the study sample with respect to the confounding variables and their association with the CHCE score.

Children who wheezed, with the exception of those with earlyonset transient wheezing, were more likely to be atopic than children who never wheezed in this period. For example, in the never-wheezed group, $18 \%$ of children were atopic, compared with $16.5 \%$ in the early-onset transient group, $24.4 \%$ in the intermediate-onset transient group, $48.6 \%$ in the early-onset persistent group, $62.4 \%$ in the intermediate-onset persistent group and $59 \%$ in the late-onset wheeze group.

\section{Wheezing patterns}

Figures $1 \mathrm{a}$ and $\mathrm{b}$, and table 2 present the unadjusted and adjusted odds ratios (95\% confidence intervals (CIs)) for the defined wheezing patterns according to CHCE z-score as a continuous variable. Increasing $\mathrm{CHCE}$ z-score was strongly positively associated with early-onset persistent wheeze and positively associated with the remaining wheezing phenotypes after adjustment for confounders. Adjustment by the confounders slightly attenuated the effect sizes of the univariable odds ratios and lengthened the $95 \%$ CIs.

Atopic status at age 7.5 yrs had a modifying effect on these associations (figs 1c and d), particularly for the nontransient wheezing groups. In nonatopic subjects, the odds ratios (95\% $\mathrm{CI}$ ) per unit increase in z-score (equivalent to four points in $\mathrm{CHCE}$ or a nonuser of a chemical versus a frequent user) for early-onset persistent wheeze were 1.41 (1.13-1.76); for intermediate-onset persistent wheeze, 1.47 (1.02-2.13); and for late-onset wheeze, $1.69(1.19,2.41$; p-values for interaction $=0.001,0.004$ and 0.006 , respectively) (fig. 1c). The odds ratios for these groups in the atopic children were all $<1$ (fig. 1d).

The odds ratios (95\% CI) for early-onset persistent, intermediate-onset persistent and late-onset wheeze in nonatopic children who were most exposed (>90th centile of CHCE score) compared with the least exposed atopic children ( $<10$ th centile of CHCE score) were 4.10 (1.07-15.76), 31.9 (1.48-687.4) and 10.72 (1.54-74.61), respectively. These figures were not further adjusted due to the small numbers in the analyses (20\% of initial sample used in the analysis).

\section{Lung function}

Lung volumes (FVC, FEV1) and mid-expiratory flows (FEF25$75 \%$ ) declined with increasing CHCE z-score (table 3). However, the effect sizes were small $(\sim 1 / 5 \mathrm{SD}$ per $\mathrm{z}$-score increase in CHCE score). Although there is some suggestion of a differential effect of atopy on these associations, the effect sizes were small and the interaction tests not significant.

Figures 1e and f present the odds ratios and 95\% CIs for the CHCE score using only VOCs and nonVOCs. There is no appreciable difference in effect sizes between the two CHCE scores.

\section{DISCUSSION}

\section{Statement of principal findings}

In a previous study, SHERRIFF et al. [1] reported a positive association between frequent use of chemicals in the home and persistent wheezing in early childhood. It has now been confirmed that these associations persist for nontransient wheezing up to $7 \mathrm{yrs}$ of age, and that they appear to be particularly strong in those children who are not atopic. This finding provides an argument against the role of the hygiene hypothesis as an explanation of the association between chemical use and wheezing. In addition, it has been observed that lung function variables at age 8.5 yrs are marginally lower in children whose mothers used chemicals in late pregnancy more frequently.

\section{Methodological considerations}

The present study was a large population-based longitudinal study that collected exposure data during the study pregnancy and outcome data after delivery and was able to consider a large number of potential confounding variables within the statistical analyses.

It was not possible to determine whether the observed associations were due to in utero exposure or whether prenatal exposure was a proxy measure for general chemical use post-natally. Post-natal CHCE scores (at 8 months post partum) were examined and a high correlation was found with the prenatal CHCE scores. Similar effect sizes were found for the outcomes; therefore, it was not statistically possible to extricate pre-natal exposure from post-natal exposure. In addition, the 
a)

LOW

IOP

IOT

EOT

Never wheeze

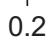
0.2

c)

\section{LOW}

IOP

IOT

EOP

EOT

Never wheeze

$$
0.0
$$

e)

\section{LOW}

IOP

IOT

EOP

\section{EOT}

Never wheeze

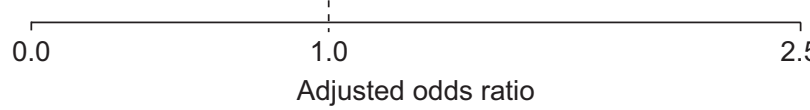

b)

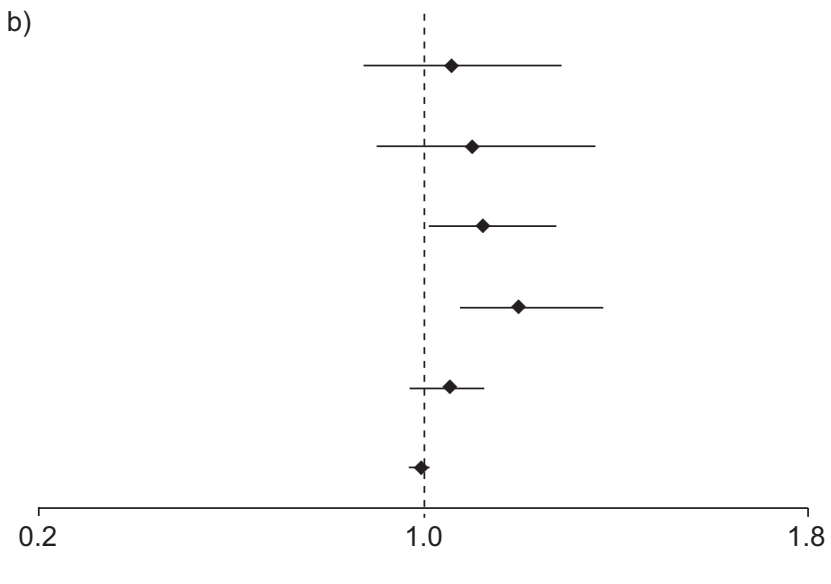

d)

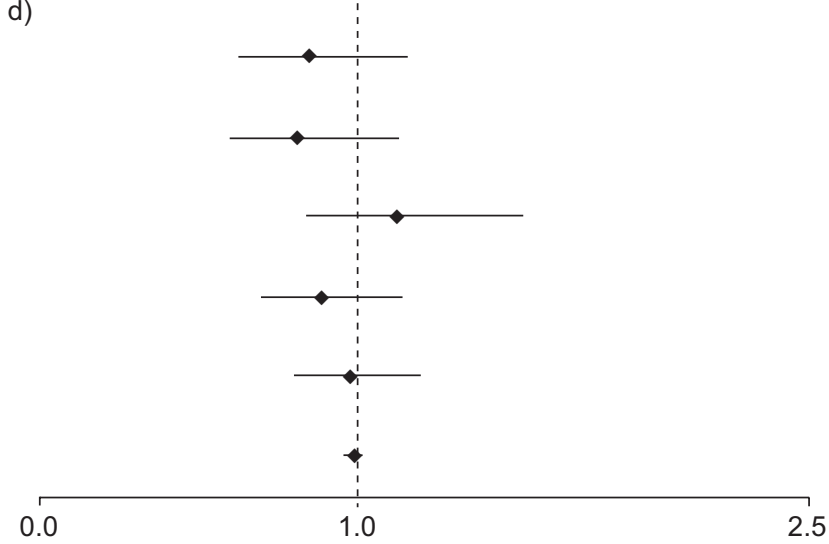

f)

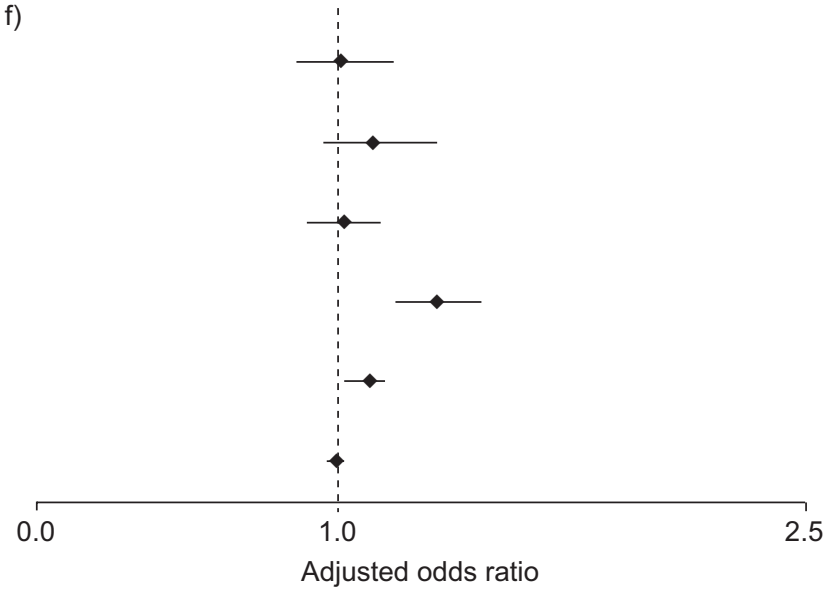

FIGURE 1. a) Unadjusted and b-f) adjusted odds ratios for wheezing phenotypes according to Composite Household Chemical Exposure (CHCE) z-score (a and b), CHCE z-score stratified for c) nonatopic and d) atopic children at age 7.5 yrs, and CHCE z-score for e) volatile organic compounds (VOCs) and f) nonVOCs. LOW: late-onset wheeze; IOP: intermediate-onset persistent; IOT: intermediate-onset transient; EOP: early-onset persistent; EOT: early-onset transient. The number of children in LOW, IOP, IOT, EOP, EOT and never wheeze groups were: a) 167, 149, 452, 413, 1,909, 4,072; b) 140, 129, 256, 317, 1,501, 3,522; c) 40, 35, 193, 105, 896, 1,971; d) 62, 56, 63, 106, 188, 433; e) 167, 149, 452, 413, 1,909, 4,072; and f) 167, 149, 452, 413, 1,909 and 4,072, respectively.

CHCE is a crude score that weights all chemicals equally. Due to the nature of the present study it was not possible to investigate individual constituents; however, individual products were examined and also dropped from the cumulative score one by one, but neither had an effect on any of the outcomes, confirming that no single product is implicated in the observed associations. All analyses were performed again using a CHCE score derived from VOCs only and one using nonVOCs. There did not seem to be a consistent pattern with either VOC or nonVOC containing chemicals in relation to wheezing phenotypes (figs $1 \mathrm{e}$ and $\mathrm{f}$ ) or any of the other outcomes. It is accepted that reported use is only a broad 


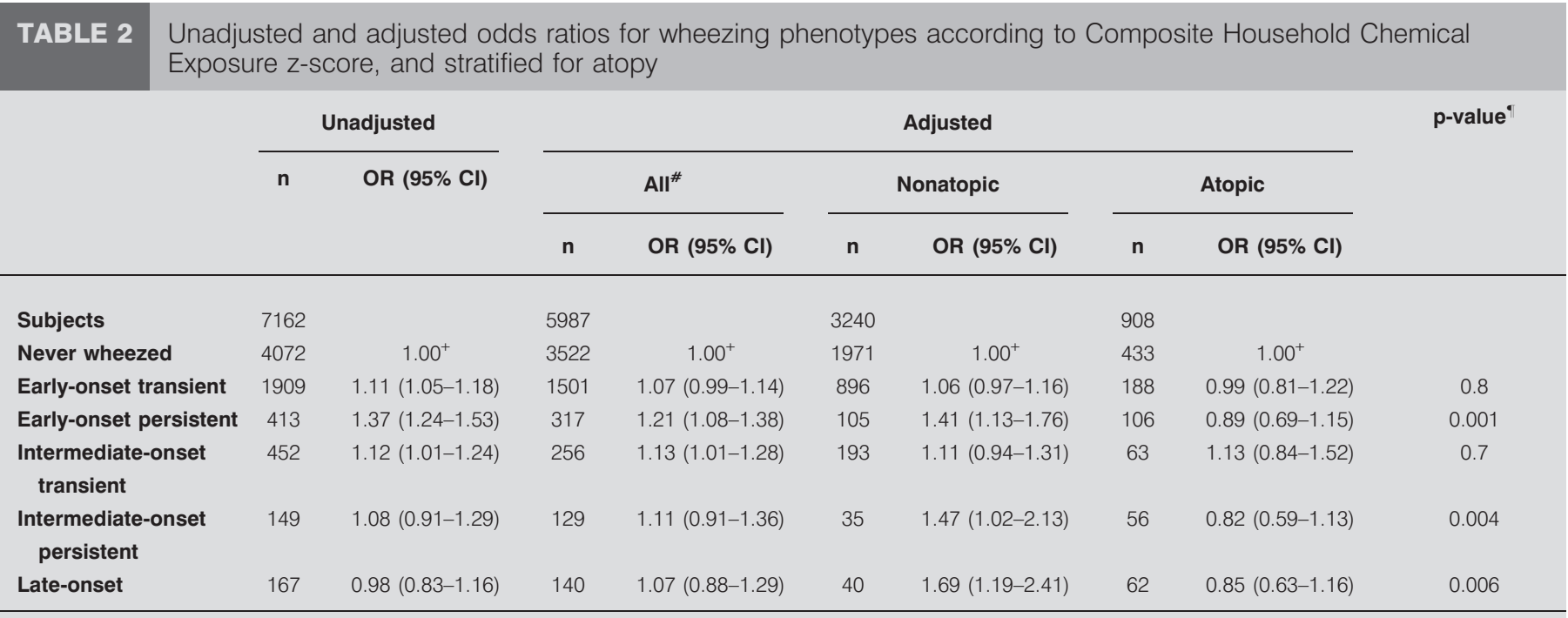

Data are presented as odds ratio $(95 \%$ confidence interval $(\mathrm{CI}))$ unless otherwise stated. OR: odds ratio. ${ }^{\#}$ : Adjusted for overcrowding in home, highest maternal education level, housing tenure, sex, exposure to environmental tobacco smoke, maternal history of asthma, maternal parity, maternal age at delivery, smoking during pregnancy, month of completion of chemicals questionnaire and maternal hours worked outside home; ${ }^{\uparrow}$ : for interaction; ${ }^{+}$: never wheezed was used as the reference value.

indicator of mother/child exposure, but it is considered a reasonably robust measure as a previous validation study on a sub-sample of ALSPAC homes demonstrated a positive association between total VOC levels and self-reported use of air fresheners and aerosols [12].

There was some selection bias among those who had complete data, that group having better educated, older mothers living in owner-occupied housing and fewer non-Caucasian children who weighed more at birth. In addition, those excluded from the analysis due to missing chemical exposure data were more likely to have wheezed at all ages than those included, and those excluded from the analysis due to missing symptom data had, on average, higher chemical exposure scores than those in the analysis.

\section{Interpretation of findings in relation to other studies}

There is now substantial evidence of an increased risk of asthma in domestic and office cleaning workers that is likely to represent a direct causal effect of chemical exposure associated with these occupations. A recently published systematic review [3] confirmed consistent associations between professional cleaning and asthma in six epidemiological studies based on either population or case-control samples. Compared with a reference population of administrative and clerical workers, ARIF et al. [7] reported an odds ratio of 2.37 for workrelated asthma associated with cleaning in the National Health And Nutrition Examination Survey III. Using similar comparison populations, JAAKKOLA et al. [15] and LE MOUAL et al. [4] also reported increased odds ratios associated with cleaning occupations but of smaller magnitude (1.42 and 1.04, respectively). Asthma has also been reported to be increased in current and former domestic cleaners compared with those never employed in domestic cleaning [5], while one study of domestic cleaners suggested that increased use of bleach among cleaners showed an exposure-response relationship for asthma when comparing intermediate with high exposure [16] This has also been described in a case series of females exposed

TABLE 3 Unadjusted and adjusted regression coefficients for Composite Household Chemical Exposure (CHCE) Z-score and lung function measures in all children and stratified for atopic status

\begin{tabular}{lcccc} 
& Unadjusted & & Adjusted & p-value \\
\cline { 3 - 5 } & & All & Nonatopic & Atopic \\
\hline FVC & $-0.031 \pm 0.013$ & $-0.026 \pm 0.016$ & $-0.03 \pm 0.02$ & $-0.012 \pm 0.04$ \\
FEV 1 & $-0.044 \pm 0.013$ & $-0.044 \pm 0.016$ & $-0.052 \pm 0.02$ & $-0.005 \pm 0.04$ \\
FEF25-75\% & $-0.032 \pm 0.013$ & $-0.033 \pm 0.016$ & $-0.046 \pm 0.02$ & 0.3 \\
\hline
\end{tabular}

Data are presented as regression coefficient $\pm \mathrm{SD}$, unless otherwise stated. FVC: forced vital capacity; FEV1: forced expiratory volume in one second; FEF25-75\%: forced mid-expiratory flow between 25 and $75 \%$ of FVC. ${ }^{*}$ : for interaction. 
to domestic bleach-hydrochloric acid mixtures [17]. In this series, the prevalence of atopy was equivalent in cases and controls, suggesting that the increased risk for asthma was not mediated by allergic mechanisms, a finding that is consistent with a study of cleaners where nonatopics exposed to lowmolecular weight agents had an increased risk of asthma compared with atopic workers [18]. Also, a surveillance study of work-related asthma in the USA [19-21] suggested that new cases were less likely to have an atopic basis than existing asthma that was work-aggravated. While this association of repeated chemical exposure and asthma has been termed "low-dose reactive airways dysfunction syndrome (RADS)", the term "irritant-induced asthma" is more appropriate [22] as RADS is regarded as requiring a (usually single) high-dose exposure to produce bronchial hyper-responsiveness. While the present study's finding of increased risk for wheezing in nonatopic children exposed to high levels of household chemicals in early life may be consistent with these observations, it was based on exploration of the hygiene hypothesis rather than an a priori hypothesis that atopy would interact negatively with chemical exposure and should therefore be subjected to confirmation in further studies. However, it gives rise to some potentially interesting insights into the mechanisms for the association between chemical exposure and wheezing illnesses in children.

It is plausible that the stronger effect observed in nonatopic subjects may be due to this particular exposure carrying a smaller risk compared with the potentially swamping effects of other exposures in atopic subjects.

These findings are consistent with the proposed possible contribution of occupational exposures to the development of or worsening of COPD [10] and, thus, the possibility exists that environmental exposures in early childhood might increase susceptibility to COPD in later life, particularly where they are associated with decrements in lung function, although the evidence for this is still largely conjectural. The question of whether lung function decrements associated with early-life pulmonary insults are reversible remains to be resolved. Longitudinal lung function data from the Tucson study of children's respiratory health [22] suggested that airway function abnormalities associated with asthma and wheezing illness that were established before 6 yrs of age did not change by age 16 yrs.

In summary, the present study has shown persistent effects on symptoms of wheeze and lung function in mid-childhood associated with exposures to a range of household chemicals during pregnancy, particularly in nonatopic children. Further investigation is required to identify the specific agents responsible and the pathophysiological mechanisms of this association.

\section{ACKNOWLEDGEMENTS}

The authors are extremely grateful to all the families who took part in the present study, the midwives for their help in recruiting them and the whole Avon Longitudinal Study of Parents And Children (ALSPAC) team (University of Bristol, Bristol, UK), which includes interviewers, computer and laboratory technicians, clerical workers, research scientists, volunteers, managers, receptionists and nurses. The authors would additionally like to thank S. Mukherjee and D. Strachan for their helpful comments during the preparation of this article.

\section{REFERENCES}

1 Sherriff A, Farrow A, Golding J, Henderson J. Frequent use of chemical household products is associated with persistent wheezing in pre-school age children. Thorax 2005; 60: 45-49.

2 Delfino RJ. Epidemiologic evidence for asthma and exposure to air toxics: linkages between occupational, indoor, and community air pollution research. Environ Health Perspect 2002; 110: Suppl. 4, 573-589.

3 Jaakkola JJ, Jaakkola MS. Professional cleaning and asthma. Curr Opin Allergy Clin Immunol 2006; 6: 85-90.

4 Le Moual N, Kennedy SM, Kauffmann F. Occupational exposures and asthma in 14,000 adults from the general population. Am J Epidemiol 2004; 160: 1108-1116.

5 Medina-Ramón M, Zock JP, Kogevinas M, Sunyer J, Antó JM. Asthma symptoms in women employed in domestic cleaning: a community based study. Thorax 2003; 58: 950-954.

6 Arif AA, Delclos GL, Whitehead LW, Tortolero SR, Lee ES. Occupational exposures associated with work-related asthma and work-related wheezing among U.S. workers. Am J Ind Med 2003; 44: 368-376.

7 Arif AA, Whitehead LW, Delclos GL, Tortolero SR, Lee ES. Prevalence and risk factors of work related asthma by industry among United States workers: data from the third national health and nutrition examination survey (198894). Occup Environ Med 2002; 59: 505-511.

8 Rosenman KD, Reilly MJ, Schill DP, et al. Cleaning products and work-related asthma. J Occup Environ Med 2003; 45: 556-563.

9 Franklin P, Dingle P, Stick S. Raised exhaled nitric oxide in healthy children is associated with domestic formaldehyde levels. Am J Respir Crit Care Med 2000; 161: 1757-1759.

10 Hnizdo E, Sullivan PA, Bang KM, Wagner G. Association between chronic obstructive pulmonary disease and employment by industry and occupation in the US population: a study of data from the Third National Health and Nutrition Examination Survey. Am J Epidemiol 2002; 156: 738-746.

11 Rumchev K, Spickett J, Bulsara M, Phillips M, Stick S. Association of domestic exposure to volatile organic compounds with asthma in young children. Thorax 2004; 59: 746-751.

12 Golding J, Pembrey M, Jones R, the ALSPAC Study Team, ALSPAC - The Avon Longitudinal Study of Parents and Children. I. Study Methodology. Paediatr Perinat Epidemiol 2001; 15: 74-87.

13 Standardization of spirometry, 1994 update, American Thoracic Society. Am J Respir Crit Care Med 1995; 152: 1107-1136.

14 Miller MR, Hankinson J, Brusasco V, et al. Standardisation of spirometry. Eur Respir J 2005; 26: 319-338.

15 Jaakkola JJ, Piipari R, Jaakkola MS. Occupation and asthma: a population-based incident case-control study. Am J Epidemiol 2003; 158: 981-987. 
16 Farrow A, Taylor H, Northstone K, Golding J, ALSPAC Study Team, Symptoms of mothers and infants related to total volatile organic compounds in household products. Arch Environ Health 2003; 58: 633-641.

17 Medina-Ramón M, Zock JP, Kogevinas M, et al. Asthma, chronic bronchitis, and exposure to irritant agents in occupational domestic cleaning: a nested case-control study. Occup Environ Med 2005; 62: 598-606.

18 Gorguner M, Aslan S, Inandi T, Cakir Z. Reactive airways dysfunction syndrome in housewives due to a bleach-hydrochloric acid mixture. Inhal Toxicol 2004; 16: 87-91.
19 Zock JP, Kogevinas M, Sunyer J, et al. Asthma characteristics in cleaning workers, workers in other risk jobs and office workers. Eur Respir J 2002; 20: 679-685.

20 Reinisch F, Harrison RJ, Cussler S, et al. Physician reports of work-related asthma in California, 1993-1996. Am J Ind Med 2001; 39: 72-83.

21 Balmes JR. Occupational airways disease from chronic low-level exposures to irritants. Clin Chest Med 2002; 23 727-735.

22 Morgan WJ, Stern DA, Sherrill DL, et al. Outcome of asthma and wheezing in the first 6 years of life: follow-up through adolescence. Am J Respir Crit Care Med 2005; 172: 1253-1258. 